\title{
Verification of the reinforced concrete beam model based on the results of a full-scale experimental study
}

\author{
Oleg Mkrtychev ${ }^{1}$, and Mikhail Andreev ${ }^{1, *}$ \\ ${ }^{1}$ Moscow State University of Civil Engineering, Yaroslavskoe shosse, 26, Moscow, 129337, Russia
}

\begin{abstract}
The article presents the results of a numerical experiment consisting in a bending test of a reinforced concrete beam and comparison of the results obtained with the results of full-scale experiments. In most cases, it is not possible to adequately consider all types of nonlinearities when using simplified bar and plate elements. The problem can be solved by using more detailed computational models with solid finite elements, allowing to consider directly the joint behavior of reinforcing bars and concrete. The studies were carried out in the LS-DYNA software package, which implemented the nonlinear concrete model - Continuous Surface Cap Model (CSCM). This model allows to consider the joint behavior of reinforcing bars and concrete, using bar (for reinforcing bars) and solid (for concrete) finite elements, thereby helping to overcome existing shortcomings in the diagrams of concrete behavior. As an object of modeling, a reinforced concrete statically determinable beam of rectangular section with dimensions of $1,000 \times 50 \times 100$ (h) $\mathrm{mm}$ is considered. The conducted studies showed that the ultimate load on the beam based on the results of numerical modeling is quite consistent with the experimental value ( $8.5 \%$ discrepancy). The arrangement of cracks and the fracture pattern obtained from the modeling results in the LS-DYNA software package are in good agreement with the results of the tests. The LS-DYNA software package will allow correct solid modeling of bending reinforced concrete elements with specification of nonlinear diagrams of concrete and reinforcing bars deformation and can be used for research, calculation and design of reinforced concrete elements of buildings and structures.
\end{abstract}

* Corresponding author: misha-andreev_93@mail.ru 
Now, we are facing lack of calculated dynamic models, which reflect the nature of the design work when calculating the maximum design earthquake (MDE). In the Russian Federation, assumptions are made on materials and types of finite elements during calculation of seismic effects on buildings and structures. Material for construction is assumed to be linearly elastic, which does not correspond to the actual behavior of the material during intense earthquakes. When creating design schemes, bar and shell finite elements are generally used. In most cases, it is not possible to adequately consider all types of nonlinearities when using simplified bar and plate elements. This applies to the zones of stress concentration, the places of joining of elements of various types, and critical units. The problem can be solved by using more detailed computational models with solid finite elements, allowing to consider directly the joint behavior of concrete and reinforcing bars.

The choice of adequate deformation diagrams or material models plays an important role in performing structural calculations in a nonlinear formulation [1]. State-of-the-art software packages, such as ANSYS, LS-DYNA, and others, allow modeling the joint behavior of concrete and reinforcing bars with the help of bar (for reinforcing bars) and solid (for concrete) finite elements. In this formulation, the diagrams presented in [2] can be used for bar finite elements.

During the research, a finite element software package LS-DYNA was used, in which nonlinear, static, and dynamic methods were implemented. In this software package, a nonlinear concrete model - Continuous Surface Cap Model (CSCM) - is implemented that allows to overcome existing shortcomings in the concrete behavior diagrams, namely, to consider the direct reinforcement of concrete with bars using solid (for concrete) and bar (for reinforcing bars) finite elements [3].

We verify the model of a reinforced concrete beam according to the results of a fullscale experimental study.

A non-prestressed reinforced concrete statically determinable beam of rectangular section is chosen as an object of modeling. Load in the form of concentrated forces was applied symmetrically. The design scheme, geometric dimensions, and the reinforcement pattern are shown in Figure 1.

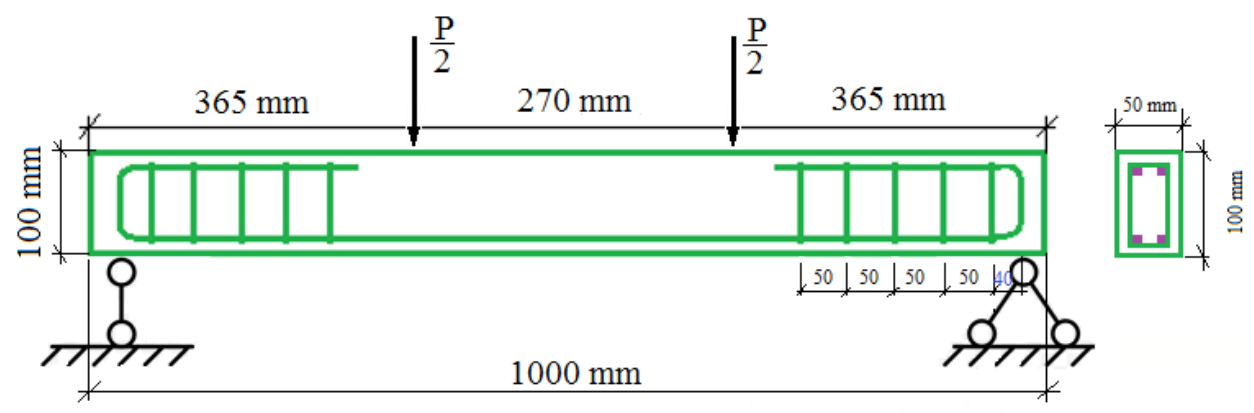

Fig. 1. Construction of reinforced concrete beams.

Let's consider the results of the beam tests. To do this, let's use the available results of experimental studies of reinforced concrete beams [4].

Full-scale experimental studies were carried out on a laboratory facility shown in Figure 2. 


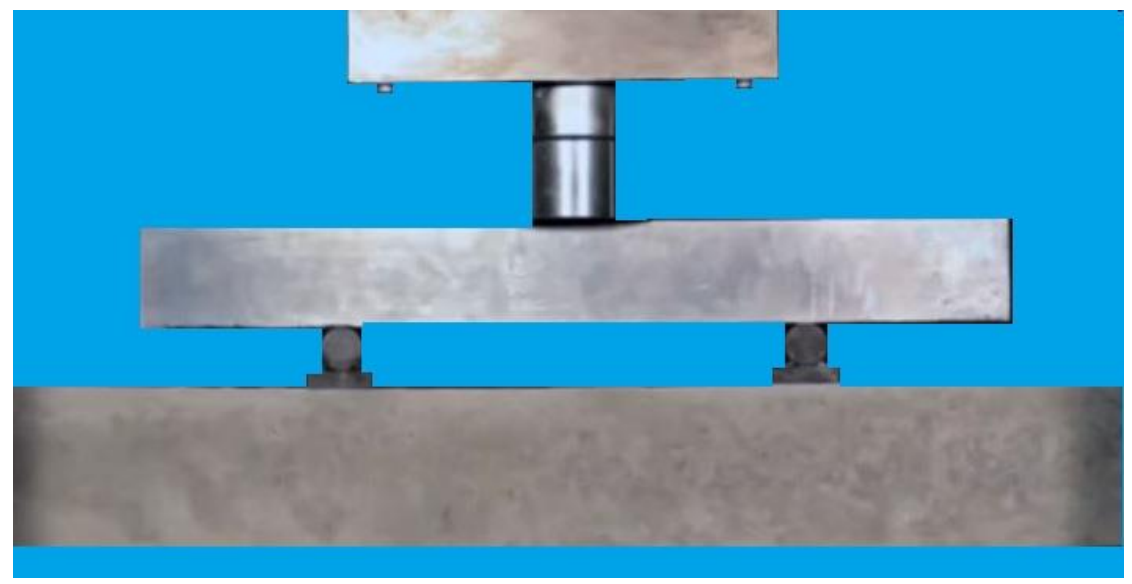

Fig. 2. General view of the experimental laboratory installation to assess the strength of reinforced concrete beams.

Figure 3 shows the fracture pattern obtained in the experimental study.

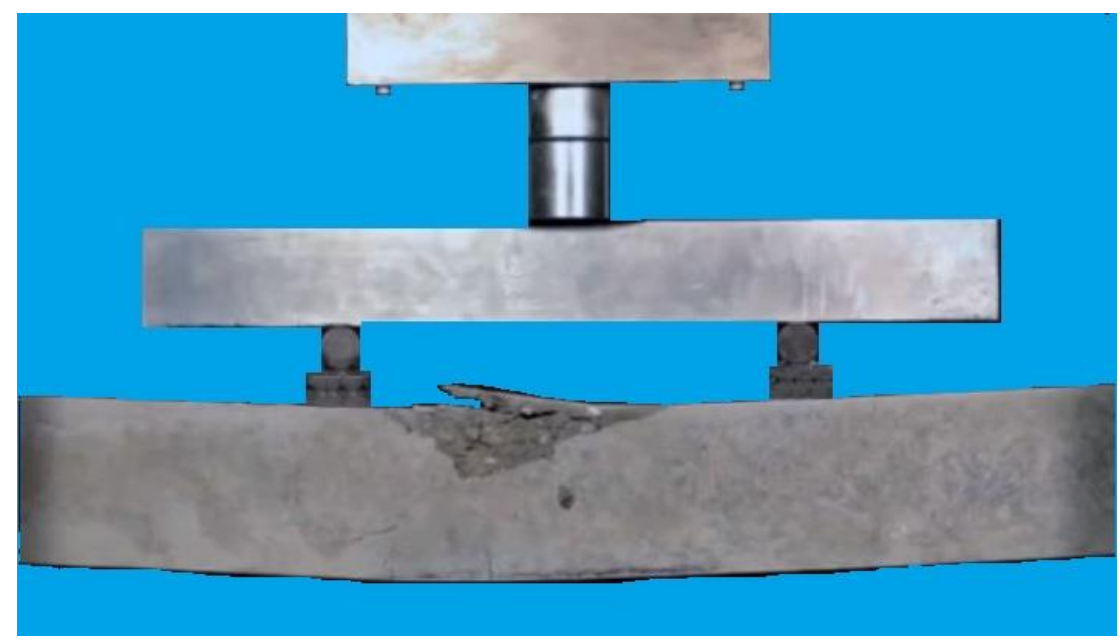

Fig. 3. Fracture of the beam during the test.

The ultimate load at which the test specimen is fractured $P_{u}=17.75 \mathrm{kN}$.

Next, let's consider modeling of the beam in the software package. The model was divided into finite elements (FE) of two types: longitudinal and transverse reinforcing bars broken into bar FE; beam concrete broken into solid FE in the form of a parallelepiped. The lower longitudinal reinforcing bar is divided into 98 bar FE, transverse reinforcing bars: vertical section - into 8, horizontal section - into 3 bar FE each. Concrete is divided into 40,000 solid FE.

The bond between the FE was implemented using the Euler-Lagrangian coupling algorithm [5].

The design model of the reinforced concrete beam and the layout of the breakdown into FE are shown in Figure 4-5. 


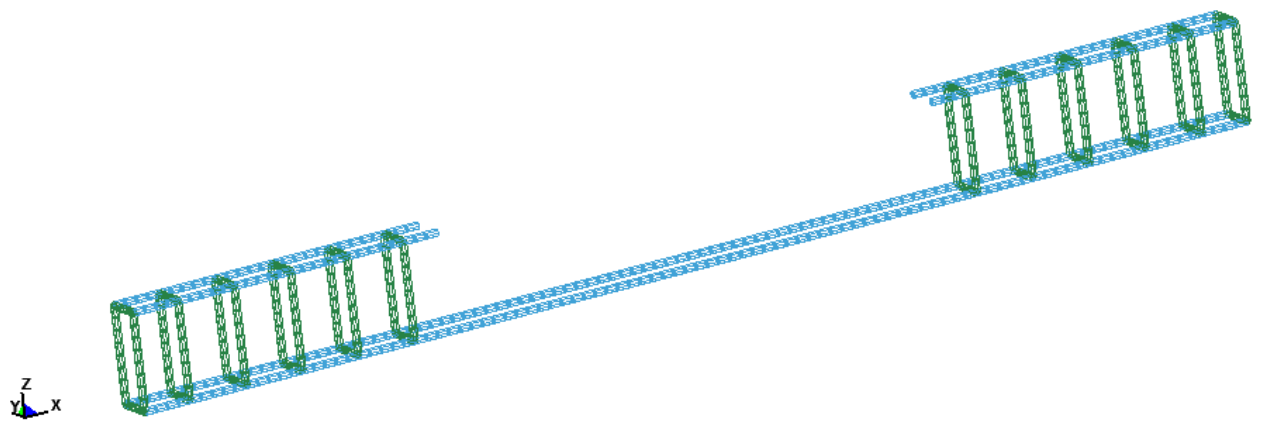

Fig. 4. Finite element discretization of the reinforcement in the beam.

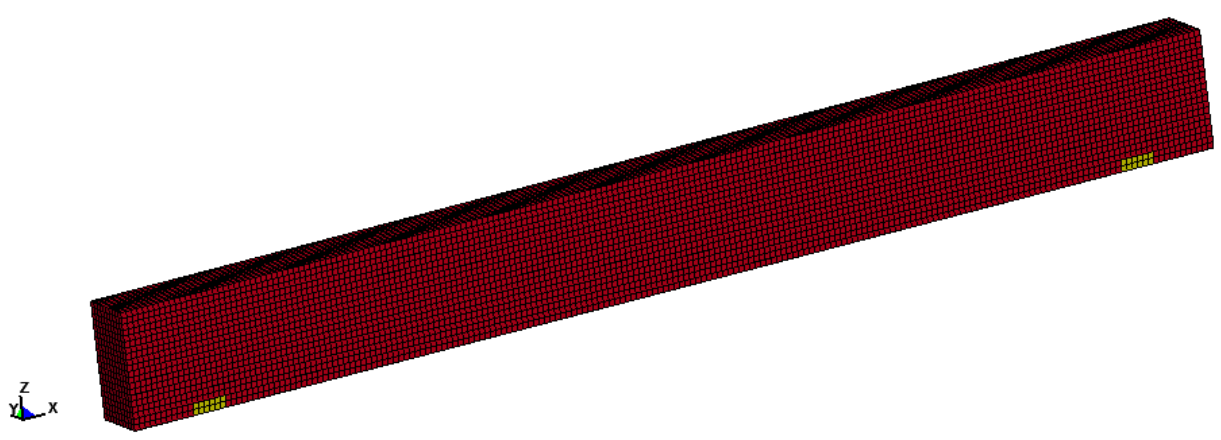

Fig. 5. Calculation scheme of the beam (volume finite elements of concrete)

Material of the reinforcing bars is steel; in the reinforcement modeling, an ideally elastic-plastic Prandtl model was used with the initial modulus of elasticity $E=2.1 \times 10^{\wedge} 5$ $\mathrm{MPa}$, the yield strength was assumed equal to $\sigma_{\tau}=500 \mathrm{MPa}$, and the limiting plastic deformations $\varepsilon_{\text {plastic }}=0.05$. The density of steel $\rho=7,850 \mathrm{~kg} / \mathrm{m} 3$. Diameter of longitudinal and transverse reinforcing bar $\mathrm{d}=6 \mathrm{~mm}$.

Nonlinear model of the CSCM material is used for concrete. Concrete corresponds to class B45 for cube compressive strength, compressive strength $\mathrm{f}_{\mathrm{cm}}=43 \mathrm{MPa}$ [6]. The density of concrete $\rho=2,400 \mathrm{~kg} / \mathrm{m} 3$.

Figure 6-10 shows the calculation results in the LS-DYNA software package.

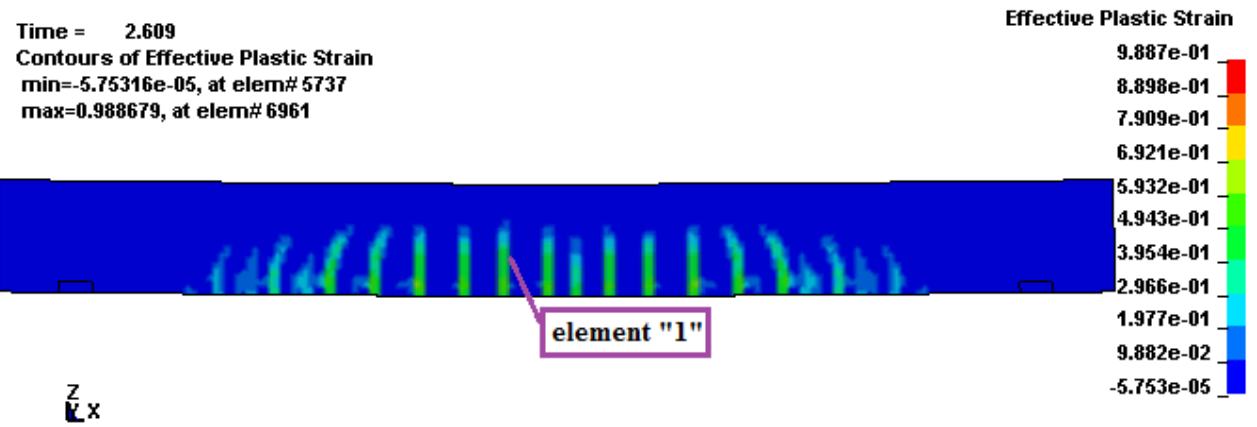

Fig. 6. The intensity of plastic deformations $\varepsilon_{\text {plastic }}(1$ on the scale corresponds to the destruction of the element). 


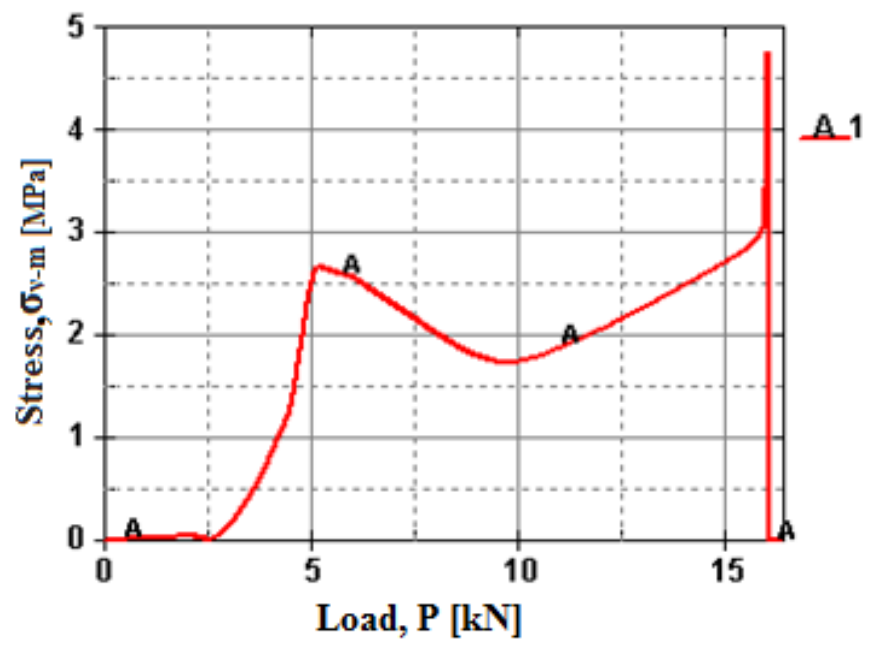

Fig. 7. The graph of stresses in the concrete element "1" of the beam in the process of loading.

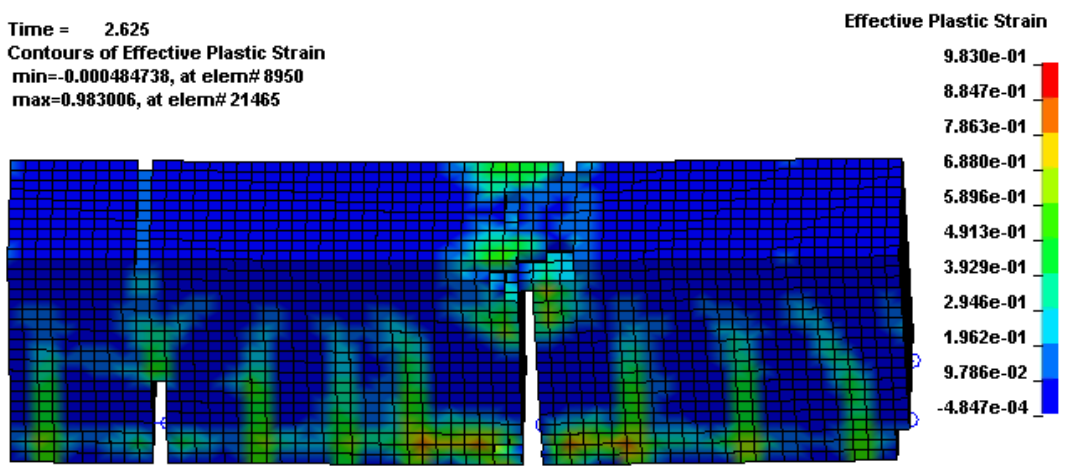

Fig. 8. The intensity of plastic deformations $\varepsilon_{\text {plastic }}$ with a detailed picture of the destruction.

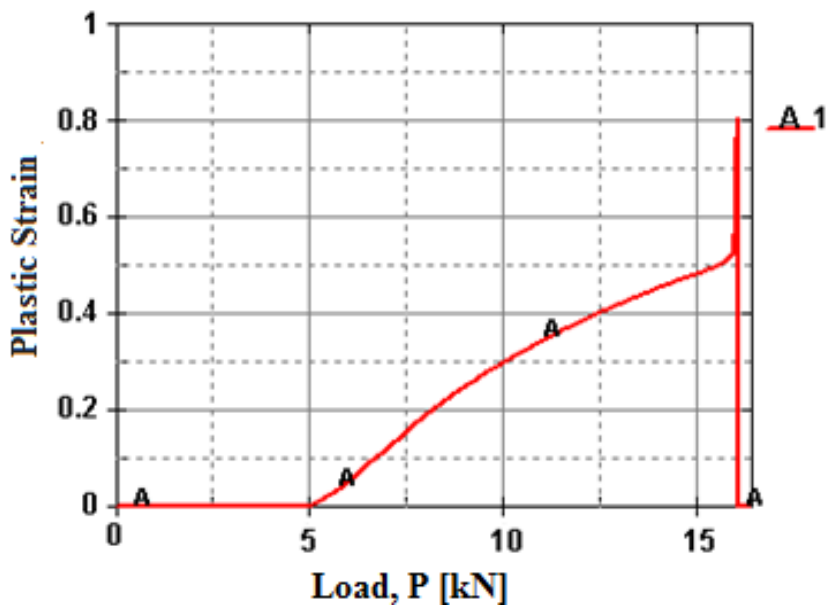

Fig. 9. Graph of change of plastic deformations $\varepsilon_{\text {plastic }}$ in the concrete element "1" of the beam in the process of loading. 
Time $=\quad 2.615$
Contours of Effe

Contours of Effective Plastic Strain

max IP. value

min=0, at elem $\$ 5403$

$\max =0.0117205$, at elem $\# 5456$
Effective Plastic Strain

1.172e-02

$1.055 \mathrm{e}-02$

$9.376 \mathrm{e}-03$

$8.204 e-03$

$7.032 \mathrm{e}-03$

$5.860 \mathrm{e}-03$

$4.688 \mathrm{e}-03$

$3.516 \mathrm{e}-03$

2.344e-03

$1.172 \mathrm{e}-03$

$0.000 \mathrm{e}+00$

\section{$y^{2} x$}

Fig. 10. The intensity of the maximum plastic deformations $\varepsilon_{\text {plastic }}$ in the reinforcement skeleton.

The ultimate load at which the beam fractures according to the modeling results $\mathrm{P}_{\mathrm{u}}=$ $16.25 \mathrm{kN}$.

\section{Conclusion}

1. The ultimate load on the beam based on the modeling results in the LS-DYNA software package is quite similar to the results of the experimental study ( $8.5 \%$ discrepancy).

2. The arrangement of cracks resulted from the modeling in the LS-DYNA software package corresponds to the results of experimental studies.

3. The overall fracture pattern resulted from modeling in the LS-DYNA software package coincides with the fracture pattern obtained in the experimental study.

4. Based on the results of comparison of the data obtained, the numerical nonlinear analysis is quite consistent with the results of the tests.

The LS-DYNA software package will allow correct solid modeling of bending reinforced concrete elements with specification of nonlinear diagrams at direct reinforcement of concrete by reinforcing bars and can be used for research (including up to the stage of fracture), calculation, and design of reinforced concrete elements of buildings and structures.

This study was performed with the financial support of the RF Ministry of Education and Science, grant \# 7.1524.2017/4.6

\section{References}

1. O. V. Mkrtychev, M. S. Busalova, Proc.Eng., 153, 475 (2016)

2. SP 63.13330.2012 Concrete and Reinforced Concrete Structures. Summary (2012)

3. O.V. Mkrtychev, MATEC Web of Conferences, 117, 00123 (2017) 
4. [Electronic resource]. URL: https://www.youtube.com/watch? $v=F l v s 5 u C n O i w /$. (date: 10.03.2018)

5. O.V. Mkrtychev, MATEC Web of Conferences, 117, 00124 (2017)

6. T. Telford Designers' guides to the Eurocodes. Designers' guides to Eurocode 2 : Design of concrete structures designers' guide to EN1992-1-1 and EN1992-1-2 Eurocode 2 : Design of concrete structures general rules and rules for buildings and structural fire design (2005) 